\title{
HUBUNGAN USIA DENGAN TINGKAT PENGETAHUAN PENGAKSES PROGRAM KESEHATAN REPRODUKSI LANSIA MELALUI RADIO DI RETJOBUNTUNG YOGYAKARTA TAHUN 2020
}

\author{
Chici Riansih $^{1}$, J Nugrahaningtyas W Utami ${ }^{2}$
}

\author{
${ }^{1}$ Program Studi D III Kebidanan Poltekkes Permata Indonesia Yogyakarta \\ ${ }^{2}$ Program Studi Fisioterapi Program Diploma Tiga Fakultas Ilmu Kesehatan \\ Universitas Respati Yogyakarta
}

Email Korespondensi : chichi.riansih@permataindonesia.ac.id, nugrahaningtyas@ respati.ac.id

\begin{abstract}
Abstrak
Pendahuluan : Pengetahuan tentang kesehatan reproduksi merupakan hal yang sangat penting, baik untuk remaja maupun lansia. Kenyataan masih banyak remaja dan lansia yang belum mengetahui mengenai kesehatan reproduksinya dengan baik. Pengetahuan tersebut dapat diperoleh dari berbagai sumber yang salah satunya adalah media massa. Tujuan penelitian ini untuk mengetahui seberapa banyak orang mengakses pengetahuan kesehatan reproduksi pada lansia. Metode penelitian ini deskriptif analitik dengan pendekatan cross sectional. Teknik sampling yang digunakan total sampling, data yang digunakan adalah data sekunder dengan populasi seluruh pemiarsa yang mengakses program kesehatan reproduksi di Radio Retjobuntung di Yogyakarta pada bulan Desember 2020. Analisis data menggunakan uji korelasi Chi Square. Hasil dalam penelitian ini pengakses program kesehatan reproduksi lansia lebih besar usia produktif dibandingkan dengan lansia dan jumlah pengakses laki-laki lebih besar dibandingkan jumlah pengakses perempuan. Sebagian besar memiliki tingkat pengetahuan yang cukup yaitu 21 responden $(51,2 \%)$. Nilai yang signifikan dengan ( $p$-value $0.001)(p<0.05)$ berarti ada hubungan yang bermakna antara usia dengan tingkat pengetahuan pengakses siaran kesehatan reproduksi di radio Retjobuntung Yogyakarta. Kesimpulan pengetahuan kesehatan reproduski masih dibutuhkan oleh orang berusia $<60$ tahun meskipun di program kesehatan reproduksi lansia. Selain itu topik kesehatan secara umum yang di akses di media massa radio adalah sama baik jenis kelamin, dan usia baik lansia maupun remaja.
\end{abstract}

Kata kunci: Kesehatan Reproduksi, Lansia, Radio

\begin{abstract}
Introduction: Knowledge of reproductive health is very important, both for adolescents and the elderly. The fact is that there are still many teenagers and the elderly who do not know about their reproductive health properly. This knowledge can be obtained from various sources, one of which is the mass media. The Objective of this study is to find out how much people access reproductive health knowledge in the elderly. The method This research is descriptive analytic with a cross sectional approach. Ssampling techniques used total sampling, data used is secondary data with the population of all initiators who access reproductive health programs at Radio Retjo Buntung in Yogyakarta in December 2020. Data analysis using Chi Square korelasi correlation test. The results in this study accessed the reproductive health program of the elderly greater productive age compared to the elderly and the number of male accessors is greater than the number of female accessors. Most have a sufficient level of knowledge, namely 21 respondents (51.2\%). a significant value with $(p$-value 0.001) $(p<0.05)$ means that there is a significant relationship between age and the level of knowledge of accessing reproductive health broadcasts on radio Retjobuntung Yogyakarta. The conclusion knowledge of reproductive health is still needed by people aged $<60$ years even in the elderly reproductive health program. In addition, health topics in general that are accessed on radio mass media are the same, both gender and age, both elderly and adolescents.
\end{abstract}

Keywords: Reproductive Health, Elderly, Radio

\footnotetext{
${ }^{1}$ Dosen Kebidanan Poltekkes Permata Indonesia Yogyakarta

${ }^{2}$ Dosen Fisioterapi Universitas Respati Yogyakarta
} 


\section{Pendahuluan}

Pengetahuan tentang kesehatan reproduksi merupakan hal yang sangat penting yang perlu diketahui. Menurut Hakim (2016) masih banyak yang belum mengetahui mengenai kesehatan reproduksinya dengan baik padahal pengetahuan tersebut dapat diperoleh dari berbagai sumber salah satunya adalah media massa.

Media massa dan media sosial dalam kehidupan sehari-hari membawa dan membetuk semacam dunia baru dalam pola pikir seseorang dalam berinteraksi dan berkomunikasi dengan cara yang baru, terutama dalam dunia pendidikan dengan menyajikan berbagai sumber informasi-informasi edukatif yang luas dari berbagai aspek (Hakim, 2016).

Lanjut usia (lansia) adalah suatu tahap lanjut dan proses kehidupan berbagai organ, fungsi serta system tubuh secara alamiah atau fisiologis agar mampu beradaptasi dengan stress dan beradaptasi dengan lingkungan. Tanda proses menua umumnya mulai tampak sejak usia 45 tahun dan akan menimbulkan permasalahan pada usia sekitar 60 tahun. Masalah kesehatan lansia melalui proses kemunduran yang panjang sehingga dapat dihambat dan dalam beberapa hal tertentu dapat dicegah. Pertimbangan lain adalah tingginya biaya pelayanan kesehatan sehingga pencegahan akan jauh lebih murah dari pada biaya pengobatan. Untuk itu upaya yang dilakukan misalnya dengan memperhatikan asupan gizi pada lanjut usia, pola istirahat lanjut usia, dan dengan memberikan olah raga contohnya senam lansia untuk para lansia (Dhewi, 2019).
Menopause adalah perubahan pada wanita ketika periode menstruasinya berhenti. Seorang wanita sudah mencapai menopause apabila dia tidak mendapatkan menstruasi selama 12 bulan secara berurutan, dan tidak ada penyebab lain untuk perubahan yang terjadi tersebut. Sebagian wanita memasuki usia 50 tahun dan menjadi tua seringkali menjadi momok yang menakutkan. Kekhawatiran ini berawal dari pemikiran bahwa dia akan menjadi tidak sehat, tidak bugar, dan tidak cantik lagi dan tidak menyenangkan, kondisi tersebut memang tidak menyenangkan dan menyakitkan (Dhewi, 2019).

Menopause merupakan berhentinya siklus menstruasi wanita yang sering dikaitkan dengan berbagai gejala yang tidak menyenangkan seperti perasaan cemas, depresi, mengalami penurunan libido, kekeringan vagina, insomnia, sult berkonsentrasi dan gejala vasomotor (hot flashes dan berkeringat $\mathrm{di}$ malam hari) (Istigosah, 2017).

Penelitian oleh Turnover mengungkapkan bahwa tingkat testosterone menurun secara permanen sekitar $1 \%$ per tahun. Penurunan ini disebabkan oleh meningkatnya konsentrasi SHBG pada tingkat 1,2\% per tahun. Menurut Pangkahila, di Amerika data menyebutkan bahwa sindroma andropause dialami oleh sekitar 15\% pria usia 40-60 tahun, tetapi hanya sekitar 5\% yang mendapat pengobatan. Perbedaan onset terjadinya andropause ini disebabkan oleh berbagai faktor. Selain dipengaruhi oleh usia yang tidak dapat diubah, juga dipengaruhi oleh faktor-faktor yang dapat dimodifikasi, seperti merokok, 
status gizi, gaya hidup, stres, dan penyakit yang diderita (Hidayatullah, 2018).

Hasil penelitian (Istigosah, 2017) didapatkan perilaku positif seksual pada usia menopause didapatkan sebanyak 4 responden (40\%), sedangkan perilaku negative seksual pada usia menopause didapatkan sebanyak 6 responden (60\%). Usia menopause mempengaruhi perilaku seksual wanita usia menopause.

Seksualitas berdasarkan WHO adalah suatu aspek inti manusia sepanjang hidupnya dan meliputi seks, identitas dan peran gender, orientasi seksual, erotitisme, kenikmatan, kemesraan dan reproduksi. Seksualitas dialami dan diungkapkan dalam pikiran, khayalan, gairah, kepercayaan, sikap, nilai, perilaku, perbuatan, peran dan hubungan. Sementara seksualitas dapat meliputi semua dimensi ini. Tidak semuanya selalu dialami atau diungkapkan. Sesualitas dipengaruhi oleh interaksi faktor biologis, psikologis, sosial, ekonomi, politik, budaya, etika, hokum, sejarah, religi dan spiritual. Sampai saat ini, seksualitas orang tua belum dibahas secara terbuka dan bebas di banyak negara (WHO dalam Pembudi, 2018).

Penelitian akhir-akhir ini menunjukkan banyak golongan lansia tetap menjalankan aktifitas seksual sampai usia yang cukup lanjut, dan aktifitas tersebut hanya dibatasi oleh status kesehatan dan ketiadaan pasangan. Aktifitas dan perhatian seksual pasangan suami istri lansia yang sehat berkaitan dengan pengalaman seksual kedua pasangan tersebut sebelumnya (Martono \& Pranarka, 2009).
Kehilangan seksualitas bukan merupakan aspek penuaan yang tidak dapat dihindari dan sebagian besar orang yang sehat tetap aktif secara seksual secara teratur sampai usia lanjut. Namun proses penuaan memang membawa perubahan tertentu dalam respon seksual fisiologis pria dan wanita, dan disertai sejumlah medis yang menjadi lebih prevalen pada usia lanjut yang berperan penting terjadinya gangguan seksual patogen terhadap lansia (Stanley \& Beare, 2016).

Pengetahuan kesehatan reproduksi menjadi sangat penting untuk remaja dan juga pada lansia karena terjadi perkembangan yang sangat dinamis baik secara biologis dan psikologis serta beberapa faktor yang mempengaruhi pengetahuan yang salah satunya adalah media massa sehingga dengan perkembangan media massa yang semakin pesat dapat juga meningkatkan pengetahuan baik remaja maupun lansia tentang kesehatan reproduksinya yang dapat mempengaruhi sikap dan tingkah laku yang bertanggung jawab mengenai proses reproduksi (Donggori, 2012).

Media masa merupakan jendela yang memungkinkan masyarakat melihat peristiwa yang terjadi di luar, cermin berbagai peristiwa yang terjadi di masyarakat dan merefleksikan apa adanya, alat penterjemah dan petunjuk arah berbagai peristiwa yang terjadi ketidakpastian atau alternative yang beragam, forum untuk mempresentasikan berbagai informasi dan ideide kepada khalayak, sehingga memungkinkan terjadinya tanggapan dan umpan balik, partner komunikasi yang memungkinkan terjadinya komunikasi interaktif. Media massa melahirkan 
informasi senagai pengetahuan oleh seluruh penggunanya (Hakim, 2016).

Penggunaan media massa secara sederhana diartikan sebagai tindakan membaca surat kabar, membaca majalah, membaca tabloid, mendengarkan radio, dan menonton televisi. Untuk menggambarkan penggunaan media massa pada lansia yang diamati adalah perilakunya dalam menggunakan media massa. Indikatornya adalah frekuensi menggunakan media, durasi atau intensitas menggunakan media, alasan dan tujuan menggunakan media, isi media yang disukai, kebiasaan-kebiasaan dalam menggunakan media seperti cara memperoleh media, waktu penggunaan dan sebagainya.

Banyak sumber yang bisa digunakan untuk menambah pengetahuan kesehatan reproduksi seperti melalui akses media massa, akses terhadap pendidikan kesehatan serta akses terhadap pelayanan kesehatan reproduksi dan lain-lain (Donggori, 2012).

Berdasarkan hasil siaran didapatkan pengakses informasi kesehatan reproduksi dan seksualitas pada lansia ini dijumpai banyak golongan usia dewasa. Tujuan penelitian ini adalah untuk mengetahui seberapa banyak orang mengakses pengetahuan kesehatan reproduksi dan seksualitas pada lansia di radio Retjobuntung Yogyakarta.

\section{Metode}

Penelitian ini menggunakan metode deskriptif analitik dengan pendekatan cross sectional. dan data distribusi frekuensi yaitu jenis kelamin dan usia. Populasi dalam penelitian ini seluruh pemiarsa yang mengakses program kesehatan reproduksi lansia di radio retjobuntung. Teknik sampel yang digunakan dalam penelitian ini adalah total sampling.

Sumber data yang digunakan pada penelitian ini adalah menggunakan data sekunder, dimana data tersebut didapatkan dari hasil pemiarsa yang melakukan interaksi dan mengakses program kesehatan reproduksi di Radio Retjobuntung Yogyakarta. Pada penelitian ini analisis data menggunakan data distribusi frekuensi yang meliputi usia dan jenis kelamin kemudian dianalisis menggunakan distribusi frekuensi. Analisis data menggunakan uji korelasi Chi Square.

\section{Hasil}

Penelitian yang dilakukan merupakan penelitian yang menggunakan data yang sudah ada dan terkumpul di dokumen penyimpanan Radio Rejto Buntung Yogyakarta. Adapun hasil yang diperoleh dapat dilihat dalam table dibawah ini.

Tabel 1.1 Distribusi Frekuensi Jenis Kelamin dan Usia Pengakses Siaran Kesehatan Reproduksi di Radio Retjo Buntung Yogyakarta 2020

\begin{tabular}{lcc}
\hline \multicolumn{1}{c}{ Jenis Kelamin } & $\mathrm{F}$ & $\%$ \\
\hline Laki-Laki & 31 & 75,6 \\
Perempuan & 10 & 24,4 \\
\hline Total & 41 & 100 \\
\hline Usia & & \\
\hline$<60$ Tahun & 39 & 95,1 \\
\hline$>60$ Tahun & 2 & 4,9 \\
\hline Total & 41 & 100 \\
\hline
\end{tabular}

Sumber: Data Primer 2020

Pada tabel 1. Menunjukkan bahwa sebagian besar pengakses siaran kesehatan reproduksi pada lansia adalah laki-laki sebanyak 31 orang atau $(75,6 \%)$, kemudian pengakses berikutnya adalah perempuan sebanyak 10 orang atau $(24,4 \%)$. Sebagian besar pengakses siaran kesehatan reproduksi pada 
lansia adalah berusia dibawah 60 tahun sebanyak 39 orang atau $(95,1 \%)$, dan untuk pengakses sedikit adalah berusia diatas 60 tahun sebanyak 2 orang atau (4,9\%).

Program kesehatan reproduksi lansia ini adalah konsektasi (konsultasi seksual dan reproduksi) yang diselenggarakan setiap hai jumat pukul 21.00 WIB.

Tabel 1.2 Hubungan Usia dengan Tingkat Pengetahuan Pengakses Siaran Kesehatan Reproduksi di Radio Retjo Buntung Yogyakarta 2020

\begin{tabular}{|c|c|c|c|c|c|c|c|}
\hline \multirow{3}{*}{$\begin{array}{c}\text { Tingkat } \\
\text { Pengetahuan }\end{array}$} & \multicolumn{4}{|c|}{ Usia } & \multirow{2}{*}{\multicolumn{2}{|c|}{ Jumlah }} & \multirow{3}{*}{$\begin{array}{c}\mathrm{P} \\
\text { Value }\end{array}$} \\
\hline & \multicolumn{2}{|c|}{$<60$} & \multicolumn{2}{|c|}{$>60$} & & & \\
\hline & $\mathrm{f}$ & $\%$ & f & $\%$ & $f$ & $\%$ & \\
\hline Baik & 3 & 7.3 & 2 & 4.9 & 5 & 12.2 & \\
\hline Cukup & 21 & 51.2 & 0 & 0.0 & 21 & 51.2 & 0.001 \\
\hline Kurang & 15 & 36.6 & 0 & 0.0 & 15 & 36.6 & \\
\hline Total & 39 & 95.1 & 2 & 4.9 & 41 & 100 & \\
\hline
\end{tabular}

(Sumber: Data Primer 2020)

Pada Tebel 1.2 menunjukkan bahwa sebagian besar responden memiliki pengetahuan cukup yaitu 21 responden $(51,2 \%)$ berusia <60 tahun, dan responden memiliki pengetahuan kurang sebesar 15 (36.6\%) dengan usia $<60$ tahun dan hanya $3(7.3 \%)$ responden memiliki pengetahuan baik dengan usia $<60$ tahun, $2(4.9 \%)$ responden memiliki pengetahuan baik dengan usia $>60$ tahun.

Hasil bivariat dengan uji Chi Square didapatkan nilai signifikan dengan ( $p$-value 0.001) $(\mathrm{p}<0.05)$ berarti ada hubungan yang bermakna antara usia dengan tingkat pengetahuan pengakses siaran kesehatan reproduksi di radio Retjobuntung Yogyakarta.

\section{Pembahasan}

Dari hasil yang diperoleh untuk jenis kelamin didapatkan hasil pengakses terbanyak adalah laki-laki yaitu 31 orang $(75,6 \%)$. Karena pada umumnya laki-laki lebih terbuka dari pada perempuan.

Dari hasil yang diperoleh sebagian besar pengakses siaran kesehatan reproduksi pada lansia adalah berusia dibawah 60 tahun sebanyak 39 orang atau $(95,1 \%)$, dan untuk pengakses sedikit adalah berusia diatas 60 tahun sebanyak 2 orang atau (4,9\%). Kebutuhan akan informasi kesehatan reproduksi dan seksualitas juga dibutuhkan oleh orang-orang yang berusia dibawah 60 tahun.

Informasi akan memberikan pengaruh pada pengetahuan seseorang. Meskipun seseorang tersebut memiliki pendidikan yang rendah tetapi jika telah mendapatan informasi yang baik dari berbagai media misalnya $\mathrm{TV}$, radio atau surat kabar maka hal itu akan dapat meningkatkan pengetahuan seseorang (Donggori, 2012).

Sebagai sarana komunikasi berbagai bentuk media masa seperti radio yang mempunyai pengaruh besar terhadap pembentukan opini dan kepercayaan semua orang. Dalam penyampaian informasi berbagai tugas yang dapat mengarahkan opini seseorang. Adanya informasi baru terbentuknya pengetahuan landasan kognitif baru terbentuknya pengetahuan terhadap hal tersebut (Mursit, 2018).

Komunikasi melibatkan perantara media yang menyebarkan informasi melalui saluransaluran yang tepat misalnya pada radio, agar masyarakat mendapat informasi yang mereka butuhkan, pada saat mereka membutuhkannya dengan cara yang masuk akal bagi mereka sehingga mereka bisa mengambil keputusankeputusan yang praktis. Setiap orang harus memahami bagaimana tubuh mereka berfungsi 
dan bagaimana menjaga dan meningkatkan kesehetan reproduksi mereka (Kementrian Kesehatan, 2016).

Memperoleh informasi kemudian hiburan banyak dinyatakan sebagai tujuan yang ingin didapatkan dalam menggunakan media massa. Pada media massa radio utamanya adalah memperoleh hiburan baru kemudian memperoleh informasi. Perkembangan media komunikasi modern dewasa ini telah memungkinkan orang diseluruh dunia untuk dapat saling berkomunikasi. Hal ini dimungkinkan karena adanya berbagai media (channel) yang dapat digunakan sebagai sarana penyampaian pesan. Media penyiaran yaitu radio merupakan salah satu bentuk media massa yang sangat efisien dalam mencapaai audiennya dalam jumlah yang sangat banyak. Karenanya media penyiaran memegang peranan yang sangat penting dalam ilmu komunikasi pada umumnya dan khususnya ilmu komunikasi massa (Ahmad, 2015).

Penelitian yang dilakukan oleh Wied Hary menyatakan beberapa faktor yang mempengaruhi pengetahuan seseorang yaitu pendidikan, pengalaman, usia serta informasi. Pengetahuan yang diperoleh dari informasi yang diberikan melalui media massa seperti radio dapat mencakup banyak hal, salah satunya ialah pengetahuan tentang kesehatan reproduksi (Donggori, 2012).

Proses pembentukan pegetahuan dimulai saat informasi dari media massa ditangkap melalui proses persepsi kemudian disimpan dan ditampilkan kembali melalui ingatan. Remaja dan lansia menyesuaikan diri dengan informasi yang diperolehnya dengan du acara yaitu asimilasi dan akomodasi. Asimilasi adalah menggabungkan informasi baru ke dalam pengetahuan yang telah dimilikinya, sedangkan akomodasi adalah penyesuaian diri terhadap informasi baru (Hakim, 2016).

Kemampuan media penyiaran radio untuk menyampaikan pesan kepada khalayak luas menjadikan media penyiaran sebagai objek penelitian penting dalam ilmu komunikasi menggunakan media massa (Ahmad, 2015).

Penelitian ini sejalan dengan (Rakhmat, 2001) menyatakan semakin banyak media massa yang digunakan remaja dan lansia untuk memperoleh informasi tentang kesehatan reproduksi maka semakin tinggi juga tingkat pengetahuan tentang kesehatan reproduksi. Dalam membangun pengetahuan lansia dan juga remaja dari informasi yang mereka peroleh dari media massa dan semakin banyak media massa yang mereka gunakan untuk mencari informasi maka semakin baik pula tingkat pengetahuan.

Hasil bivariat dengan uji Chi Square didapatkan nilai signifikan dengan ( $p$-value 0.001) $(\mathrm{p}<0.05)$ berarti ada hubungan yang bermakna antara usia dengan tingkat pengetahuan pengakses siaran kesehatan reproduksi di radio Retjobuntung Yogyakarta. Penelitian ini sejalan dengan penelitian (Mardiana, 2012) yang menyatakan bahwa ada hubungan aktifitas seksual pra lansia dan lansia yang terdapat pada faktor usia. Salah satu faktor yang berhubungan dengan tingkat pengetahuan seseorang adalah usia. Dimana semakin bertambahnya usia seseorang maka semakin bijaksana dan banyak pengalaman atau hal yang 
telah dijumpai dan dikerjakan untuk memiliki pengetahuan.

\section{Menurut Setiyani (2013) Tingkat} pengetahuan seseorang dapat mempengaruhi seseorang dalam berperilaku. Tingkat pengetahuan yang tinggi cenderung akan berperilaku lebih baik jika di bandingkan tingkat pengetahuan rendah. Tingkat pengetahuan yang tinggi akan mampu menyerap informasi dengan lebih baik dan dapat memilih antara informasi yang baik dan buruk. Informasi yang telah didapatkan dapat menjadi acuan dalam berperilaku.

Pada penelitian ini sebagian besar responden berusia $<60$ tahun sebanyak 21 responden $(51,2 \%)$. Dengan tingkat pengetahuan cukup. Hal ini menunjukkan bahwa orang yang berusia $<60$ tahun juga sebagai pengakses program kesehatan reproduksi lansia. Notoatmodjo (2003) menyatakan bahwa tingkat pengetahuan merupakan domain yang sangat penting dalam membentuk tindakan seseorang sedangkan perilaku akan bersifat langgeng apabila didasari pengetahuan dan kesadaran.

Menurut Lee (2007) penting untuk menyadari suatu pengetahuan tentang masalah yang berhubungan dengan kesehatan dan masalah psikologis, disamping perubahan fisik yang disebabkan oleh proses penuaan yang dapat menjadi faktor yang mempengaruhi seksualitas pada lansia.

Pengetahuan juga dapat mempengaruhi persepsi seseorang tentang keinginan dan perasaannya terhadap seksualitas pada masa lansia, sehingga antara pengetahuan dengan seksualitas lansia terdapat hubungan yang positif (Sari, 2016).

\section{Kesimpulan}

Dari hasil peneltian ini diperoleh kesimpulan yang garis besarnya adalah bahwa kegiatan yang sering digunakan untuk mengisi waktu luang lansia adalah mendengar radio. Ketika disilangkan antara topik dengan jenis kelamin menunjukkan kecendrungan yang sama terhadap topik yang sering menjadi konsumsi media massa yaitu masalah kesehatan dan tidak ada perbedaan antara usia lansia dan usia remaja dalam mengakses media massa radio.

Radio sebagai media massa elektronik tentunya lebih memudahkan sarana informasi. Disinilah urgensinya teknologi informasi dapat digunakan sebagai penyampaian pesan-pesan kesehatan reproduksi. Radio juga mampu memberikan manfaat yang sangat luas. Keunggulannya mencapai efisiensi ruangm sehingga mampu menghasilkan informasi dalam waktu yang singkat. Oleh karena itu radio sangat praktis dan efisien untuk suatu sarana media massa yang bersifat informasi

Didapatkan nilai yang signifikan dengan ( $p$-value 0.001$)(\mathrm{p}<0.05)$ berarti ada hubungan yang bermakna antara usia dengan tingkat pengetahuan pengakses siaran kesehatan reproduksi di radio Retjobuntung Yogyakarta.

\section{Daftar Pustaka}

Ahmad, N (2015). Radio Sebagai Sarana Media Massa Elektronik. Vol 3 No 2 Desember 2015.

Dewi, F.K (2018). Program Integrasi Lansia dan Reproduksi (Pilar) di Bina Keluarga Lansia dan Bina Keluarga Remaja. GEMASSIKA : Jurnal Pengabdian 
Kepada Masyarakat. Vol. 2 No. 2 November 2018.

Dhewi, Siska (2019). Perilaku Lansia Pada Masa Menopause di Posyandu Lansia Desa Tambak Baru llir Martapura. Faletehan Health Journal, 6 (2) (2019) 75 - $81 . \quad$ www.journal.lppmstikesfa.ac.id/ojs/index.php/FHJ

Donggori, R.I (2012). Hubungan Akses Media Massa Dengan Pengetahuan Kesehatan Reproduksi Pada Remaja. Jurnal Media Medika Muda. Universitas Diponegoro.

Harianti, R (2016). Karakteristik, Pengetahuan dan Sikap Pasangan Usia Subur Tentang Penyakit Menular Seksual di Klinik Y Kabupaten Indragiri Hulu. Jurnal Kesehatan Reproduksi Vol 7, No. 3 pp 199 - 209 (2016).

Hakim, Abdul (2016). Pengaruh Informasi Media Massa Terhadap Pengetahuan Kesehatan Reproduksi. Psycho Idea, Tahun 14 No. 1, Februari 2016

Hidayatullah, S (2018). Faktor-Faktor yang Berhubungan dengan Kejadian Andropause Pada Pria Usia 30-50 Tahun (Studi di Kecamatan Pedurungan Kota Semarang). Jurnal Kesehatan Masyarakat (e-Journal) Vo 6, Nomor 1, Januari 2018.

Istigosah, N (2017). Perilaku Seksual Pada Usia Menopause di Posyandu Lansia Dahlia RW 9 Kelurahan Dandangan. Jurnal Kebidanan Dharma Husada. Vol 6, No 2 Oktober 2017.

Kementrian Keehatan RI. Riset Kesehatan Dasar (2013). Jakarta: Balitbangkes; 2014

Khotimah, N (2016). Lanjut Usia (LANSIA) Peduli Masa Depan di Daerah Istimewa Yogyakarta. Jurnal Geomedia, Volume 14 Nomor 2 November 2016, hal 51-65

Kemetrian Kesehatan RI(2016). Kesehatan Reproduksi dan Keluarga Berencana. Pusdik SDM Kesehatan.

Kumar, R dan Safee (2014). Assessment Of Morbidity Pattern And Its Correlates Among Elderly Population In Rural Area Of Perambalur, Tamilnadu, India. International Journal of Biomedical Research.

Lee, K.J. (2007). A Study On Knowledge And Attitudes Regarding Sexuality Of Elderly People In Korea. Journal Of Korean Academy Of Nursing Vol. 37, No. 2, halm. 179-184.
Martono, H \& Pranarka, K (2009). Ilmu Kesehatan Usia Lanjut. Jakarta: Balas Penerbit FKUI

Mardiana (2012). Aktivitas Seksual Pra Lansia dan Lansia yang Berkunjung ke Poliklinik Geriatri Rumah Sakit Pusat Angkatan Udara DR. Esnawan Antariksa Jakarta Timur. Universitas Indonesia.

Meltzer PS, Kallioniemi A, Trent JM. Chromosome Alterations in Human Solid Tumors. Dalam: Vogelstein B, Kinzler KW, editor. The Genetic Basis of Human Cancer. New York: McGrawHill; 2002. Halaman 93-113.

Massie, Roy G.A (2019). Akses pelayanan yang tersedia pada penduduk lanjut usia wilaya perkotaan di Indonesia. Jurnal Penelitian dan Pengembangan Pelayanan Kesehatan, Vol. 3, No. 1 April 2019

Mursit, H (2018). Hubungan Pengetahuan Tentang Kesehatan Reproduksi Dengan Sikap Pencegahan Terhadap Kehamilan Remaja di SMKN Saptosari, Gunungkidul Tahun 2018. Poltekkes Yogyakarta. Prodi Sarjana Terapan Kebidanan.

Notoatmodjo, S. (2003). Ilmu Kesehatan Masyarakat Prinsip-prinsip Dasar. Rineka Cipta. Jakarta.

Pambudi, H A (2018). Pandangan Lansia tentang Seksualitas pada Lanjut Usia. Jurnal Kesehatan. Volume 9 Nomor 1 April 2018.

Rakhmat, D (2001). Metode Penelitian Komunikasi. Bandung : PT Remaja Rosdakarya.

Sari, K R (2016). Hubungan Tingkat Pengetahuan tentang Seksualitas dengan Aktivitas Seksual Pada Lansia di Dusun Panggang Bumirejo Lendah. Universitas 'Aisyiyah Yogyakarta.

Setiyani. (2013). Hubungan Tingkat Pengetahuan Tentang Seksualitas Dengan Perilaku Seksual Remaja Di SMK Negeri 1 Sewon Bantul Yogyakarta. Skripsi tidak dipublikasikan.

Stanley, M., \& Beare, P. G. 2016. Buku Ajar Keperawatan Gerontik (2nd ed.). Jakarta: EGC. 